\title{
Computerized Optimum Dimensioning of Prestressed Homogenous Steel I-Beam
}

\author{
Markandeya Raju Ponnada ${ }^{1, a, *}$, and Ravindra Vipparthy ${ }^{2, b}$ \\ 1 Maharaj Vijayaram Gajapathi Raj College of Engineering(A), Vizianagaram, Andhra Pradesh 535005, India \\ 2 Jawaharlal Nehru Technological University Kakinada, Kakinada, Andhra Pradesh 535005, India \\ E_mail: amarkandeyaraju@gmail.com (Corresponding author), bravindra.vipparthy@gmail.com
}

\begin{abstract}
The economy of a prestressed steel beam can be realized only when relevant parameters of optimum magnitude are chosen. The present work aims at finding out the optimum dimensions of a simply supported, laterally unsupported, prestressed steel Ibeam for a given span and load carrying capacity. The span of the beam was limited to 12 $\mathrm{m}$ while the load carrying capacity was limited to $100 \mathrm{kN} / \mathrm{m}$ in this study. A straight tendon configuration over the whole span is considered and the losses occurring in the tendon are neglected. The safety of various sets of dimensions ranging from the minimum dimensions of I-section in IS-Hand Book-1 to their maximum dimensions for different pre-stressing forces and eccentricities are checked. The set with minimum cross sectional area is chosen. Iterative calculations involved in analysis were performed with the help of a ' $\mathrm{C}$ ' program developed by the authors in Turbo 'C' Environment. It was observed that the ratio of top fiber stress at working loads to the permissible stress is more than 0.9 for all the spans for the finalized cross-sections. This means that the cross-section is being effectively utilized. For a given load carrying capacity and span, eccentricity to depth ratio has to be in between 0.45 to 0.7 for optimum utilization of the available cross section. It is also observed that the maximum pre-stressing force equal to 0.25 times the permissible bending compressive stress can be applied.
\end{abstract}

Keywords: Prestressed steel beam, eccentricity, tendon profile, optimum dimensions, check for safety.

ENGINEERING JOURNAL Volume 21 Issue 7

Received 19 March 2017

Accepted 18 July 2017

Published 29 December 2017

Online at http://www.engj.org/

DOI:10.4186/ej.2017.21.7.293 


\section{Introduction}

The necessity for economy in steel in view of large quantities needed for construction and rehabilitation of various steel structures necessitated the requirement of saving steel. The concept of pre-stressing is not a new frontier in the field of Civil Engineering. The concept of prestressing steel structures is only recently being re-considered, despite a long and successful history of pre-stressing concrete members. In spite of having many advantages over pre-stressed concrete, pre-stressed steel has not been popular due to the complexity and ambiguity involved in analysis and design calculations and problems arising due to application of external prestressing technique and fabrication. The idea of prestressing of steel may be surprising to many Engineers. Being familiar with pre-stressed concrete, they will not be convinced with the application of the same principles to constructions made in structural steel. But it is to be noted that they are valid because the assumptions involved in formulating them are more valid for steel beams than for concrete beams. The advantages of a pre-stressed steel beam can be realized only when the cross-section is effectively utilized.

\section{Literature Review}

Little research has been done in the area of prestressed steel beams. A summary of some of the important works in this area is presented below.

Pre-stressed metal structures have been proposed since 1837, when Whipple (1847) [1] in the United States learned to compensate for the poor tensile capacity of cast-iron members through pre-stressing in Bridges. Dischinger (1949) [2] in Germany, beginning in 1935, began to conceive much wider applications for pre-stressed steel. His proposals included highway and railway bridges utilizing pre-stressed plate girders, box girders, trusses and other structural forms. Fritz. (1955) [3] reaffirmed the work. As a result of the European work in pre-stressed steel, Coff (1950) [4] in the United States proposed a 250-foot span prestressed steel plate Girder Bridge. He later patented a pre-stressed composite system. Another U.S. patent was granted to Naillon in 1961 for pre-stressing of a steel beam by cables. Magnel (1950) [5] reported experimental results from a steel truss pre-stressed by post-tensioning of the tension chord. Strands were placed inside the hollow chord and tensioned against anchorages at the ends of the chord. A later article by Magnel (1954) [6] described one of his projects, a pre-stressed long span roof truss for a Belgian aircraft hangar. He stated that pre-stress loss was only $9 \%$ (which is relatively low compared to losses for prestressed concrete). Barnett (1957) [7] returned to the queen post truss concept in suggesting the use of prestressed steel truss beams. In the late 19th and early 20th centuries, Barnard (1960) [8] designed many U.S. bridges with trussed floor beams. Vasiliev (1961) [9] analysed the behavior of pre-stressed beam with a view to determine optimum geometric parameters. He also studied the effect of various types of loading patters upon optimum parameters. Finn and Needham (1964) [10] performed a rather extensive testing program for a 90 -foot span pre-stressed steel truss. Petrov $(1965,1967)[11,12]$ examined the parameter of prestressed steel beams for designing with cables all along the beam length. The equations derived by Vasiliev (1961) [9] were used and the results were presented in the form of graphs. Petrov (1967) [12] indicated also the drawbacks of his previous design method in the subsequent work. Subcommittee 3 (1968) [13] of the Joint ASCE-AASHTO Committee on Steel Flexural Members reviewed the state of the art in pre-stressed steel. Ekberg (1968) [14] reported the conclusions of the committee. Ferjencik (1972) [15] and Tochacek and Amrhein (1971) [16] described progress in pre-stressed steel design in Czechoslovakia. Research was begun in 1960, and actual design specifications were adopted as a result of that research. Ferjencik described a rather extensive catalog of applications of pre-stressing including applying it to girders and trusses. Tochacek and Mehta (1972) [17] pointed out that the safety factor for the portions of pre-stressed steel structures subjected to a range of both tension and compression can be reduced by up to $20 \%$ under a working stress design. In order to give an adequate and consistent factor of safety, he suggested use of load factor design. Belenya (1972) [18] conducted tests on pre-stressed homogenous beam. The beam cross sections are asymmetric with bottom flange made of plate, pipe or angle. Kalburgi (1975) [19] developed the equations for finding optimum pre-stressed steel I-section in non-dimensional parameters. Soliman et al. (1986) [20] analysed uniformly loaded steel continuous beams for variable cross section in elastic and elasto-plastic behavior. Expressions are developed for determining the optimum values of certain parameters that influence the effectiveness of the prestressed member. It was observed that the load carrying capacity depends on length to depth ratio and depth to thickness of web of section. Michael S. 
Troitsky et al. (1989) [21] made a study on pre-stressed - steel continuous - span girders. Pre-stressed steel girders having either simple or continuous spans are indeterminate structures. Mark A. Bradford (1991) [22] made a study on buckling of pre-stressed steel girders. Pre-stressing of steel girders, in order to gain economy of the material, is becoming popular in the United States. Rao (1993) [23] suggested a direct method for optimum design of pre-stressed metal beams working with elastic and elasto-plastic states. The equations derived were in general form an arbitrary location of the cable along the height of the section. Russel and Syder (1995) [24] made a study on pre-stressed steel girders for single span bridges. Valiente and Elices (1998) [25] reported prestressed steel bars failure details and failure analysis is done using Linear Elastic Fracture Mechanics. They showed that the ususal design requirements for prestressing bars fail to warn against brittle failures if damage exists. Knowledge of the toughness of the prestressing bars may be helpful to the designer and builder to compare, select or reject different batches. Nunziata et al. (1999) [26] made a study on various methods of analysis of pre-stressed steel structure design. Raman Singh et al. (2002) [27] made a case study on pre-stressed steel bridge. Guptha (2002) [28] made a study on pre-stressed steel structures. In his keynote address he briefed the behavior of pre-stressed steel structures like prestressed steel frames, pre-stressed steel trusses etc. Optimum parameters for design of pre-stressed steel structures are listed out towards the end. Brodka and Klobukovki (2002) [29] developed ATOM bridge construction method. It maximises the economic effect and improve the construction convenience when compared with existing methods. Nunziata et al. (1999) [26] conducted an experimental study on structures in pre-compressed steel. The basic principles and the technology of pre-stressing steel structures were discussed. $40 \mathrm{~m}$ long pre-stressed steel beams were tested by loading concrete blocks of weight $25 \mathrm{kN}$ each. The results were consistent with those obtained by applying the analytical procedure proposed by the author. Yusuf Ozcatalbas and Alpay Ozer (2007) [30] studied mechanical properties of internally prestressed steel I-beam. It was observed that permanent stresses and the magnitude of pre-deflection in the prestressed I- beams change with the level of prestressing. Decreasing the magnitude of prestressing resulted in an increase in the flexural capacity of prestressed steel I-beams. Ravindra et al. (2008) [31] formulated a procedure for analysis and design of pre-stressed steel beams. ISWB 600 is taken for the execution of the program for various combinations of span. It was concluded that a minimum eccentricity is required for the beam to be safe in all respects and it is observed that there is no significant improvement in the load carrying capacity by applying maximum allowable prestressing force with minimum allowable eccentricity. Belletti and Gaspen (2010) [32] reported the behavior of simply supported Steel I-beams by prestressing with tendons. They opined that stress losses in tendons are not considered because friction losses are negligible for un-bonded tendons and relaxation losses are negligible. They focused on fundamental parameters like the number of deviators and the magnitude of prestressing force. Nonlinear finite element analyses is used by taking into account both mechanical and geometrical nonlinearities. It was recommended based on this study that two deviators should not be adopted to impose the shape of tendon for practical solutions. Further, it was observed that, for an assigned number of deviators and for the same prestressing force, a better performance is achieved by tensioning after the bracing is applied. Sunkyu Park et al. (2010) [33] studied the flexural behavior and strengthening effect of externally prestressing a steel Ibridge with un-bonded tendons and observed that external prestressing creates a stiffer steel beam when an appropriate magnitude of the prestressing force is applied. The results are compared with theoretical solution in order to establish their practical applicability. It was observed that the yield and ultimate loading of steel I-beams significantly increased. It was further concluded that the amount of prestressing force applied, the installation of a deviator and the embedment of a draped tendon may be significant factors that influence the strengthening of steel I-beams. Ravindra and Markandeya Raju (2012) [34] formulated a procedure for finding loss of prestress in prestressing steel beams and studied the performance of prestressed steel I-beams and compound beams with and without loss of prestress. It was observed that the load carrying capacity calculated by neglecting losses is less when compared with that calculated by considering losses. However, not much change in the eccentricity required for achieving maximum load carrying capacity was observed. Jae-Yue Oh et al. (2012) [35] proposed two rational and theoretical models to quantitatively estimate the accordion effect, which is induced by the introduction of prestress to corrugated webbed steel beams. They performed experiments on two steel beams with corrugated webs and one with typical wide flange section. Based on the finite element analysis, it was confirmed that the accordion effect induced in steel beams with corrugated webs at the prestress transfer was greatly dominated by the geometric characteristics of corrugated webs, and it can be simply quantified using key factors. The experimental results showed that the prestressing efficiency of steel beams with corrugated webs increased more significantly than that of the steel beam with a typical web, and it is verified that the 
proposed methods are very simple and provide good agreements with the experimental results. Ponnada and Vipparthy (2013) [36] compared the performance of prestressed steel I-beam and that strengthened in compression by welding two angles. The study of the variation among different parameters revealed that the load carrying capacity is not directly proportional to the prestressing force in case of an unsymmetrical I-section for eccentricities less than a minimum value. But in case of a symmetrical section, the load carrying capacity is directly proportional to the prestressing force for all eccentricities. However, it was observed that the material of the cross-section is effectively utilised when an unsymmetrical I-section is prestressed. Vipparthy and Ponnada (2013) [37] developed an algorithm for evaluating the performance of prestressed symmetric and unsymmetrical steel I-beams. For each of the rolled steel beam sections available in IS - Hand Book 1 and for spans varying from $8 \mathrm{~m}$ to $16 \mathrm{~m}$, iterative calculations involved in analysis have been performed with the help of a program developed by the authors for analysis of prestressed steel beams. The advantage of prestressing steel I-beams strengthened in compression is more than that gained by prestressing symmetrical I-beam because the range of eccentricity available for prestressing is more. The study revealed that the range of eccentricity that can be provided for I-section is less than that for I-section strengthened in compression by welding a plate. Raju Ponnada and Vipparthy (2014) [38] proposed a method of arriving at expression for deflection of simply supported, prestressed homogenous steel I-beams calculated by considering the combined effect of prestressing and total load. A straight tendon configuration with an eccentric prestressing force is considered for study. Ravindra and Markandeya Raju (2007) [39] developed a program for Optimum Design of an Unsymmetrical, Laterally Unsupported Prestressed Homogenous Steel I- Beam. Pothisiri and Hemathulin (2012) [40] presented the test data on intumescent fire protection for Structural Steel Sections in Thailand. Lenwari and Chen (2012) [41] conducted Finite Element Analysis of Distortion-Induced Web Gap Stresses in Multi-I Girder Steel Bridges. Lenwari and Thepchatri (2015) [42] presented an optimum design of Steel Structures in Accordance with AISC 2010 Specification Using Heuristic Algorithm. Phuvoravan and Ponsorn (2017) [44] performed a nonlinear Finite Element Analysis to evaluate lateral torsional buckling moment of elliptical cellular steel beams.

The recent developments in the prestressed metallic carpentry demonstrate that there is vast scope for research and development in this area. However, this technique is not very famous in the Construction industry. Studies on the Optimization of the steel cross-sections can demonstrate the advantage of prestressing steel beams over normal steel beams.

\section{Behavior of Prestressed Steel I-Beam}

\subsection{General Considerations in the Design of Prestressed Steel Beams}

Beams are considered to be the most critical members in any structure. Hence their design should be economical and safe. The Main considerations in the design of steel I-beams are as follows:

1) They should be proportioned for strength in bending keeping in view lateral and local stability of the compression flange and the capacity of the selected shape to develop the necessary strength in shear and local bearing.

2) They should be proportioned for stiffness, keeping in view their deflections and deformations under service conditions. They should be proportioned for economy with regards to the size and grade of steel to arrive at the most economical design. It is a difficult task for designer to select an economical beam size (particularly for steel beams) for given span and load that will satisfy above all three conditions.

3) A number of rolled steel sections are used in construction. However, angle and T-sections are inherently weak in bending while channels can only be used for light loads. I-shape is preferred because it can effectively take heavy loads. Further it is easy to predict the lateral buckling characteristics and it is also possible to split and rejoin by welding. Such beams are more resistant to bending by virtue of their high section modulus. Also, the load carrying capacity of a steel Ibeam can be considerably enhanced by prestressing it.

\subsection{Ideal Stress-distribution in Prestressed Steel Beams}

Prestressing of I-shaped steel beam can be performed in one of the two basic ways. One is to place tendon below centroid of beam section and above bottom flange (Fig. 1(a)) and attach them at each end of beam. 
In this case a constant eccentric prestressing force is applied. Second method is to place tendon below beam fiber (outside beam a in Fig. 1(b)) in tension. The prestressing force applied creates two normal stress components, axial and bending. Top and bottom flanges are subjected to tension and compression respectively. This distribution of stress is opposite to the stress caused by down ward applied load. When transverse loads (including both live and dead load) are applied, resulting bending stresses add to stresses due to prestressing to give final combined stress distribution.

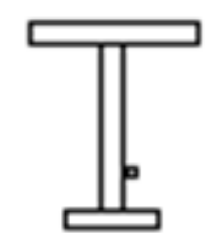

c/s of the beam

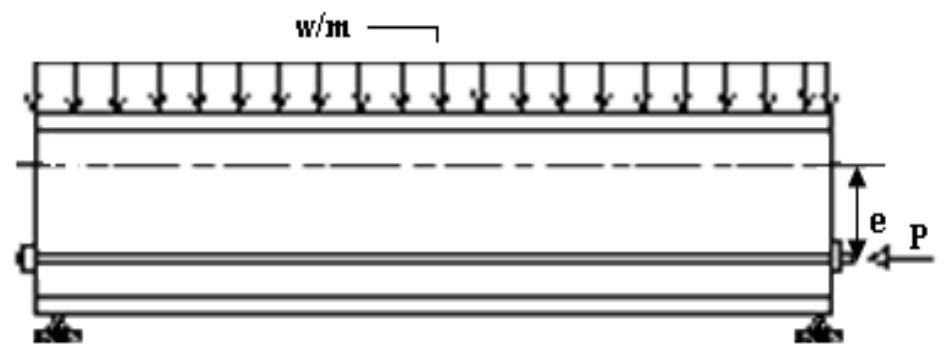

L/s of the beam

Fig. 1. (a) Tendon placed inside the cross-section of a loaded beam.

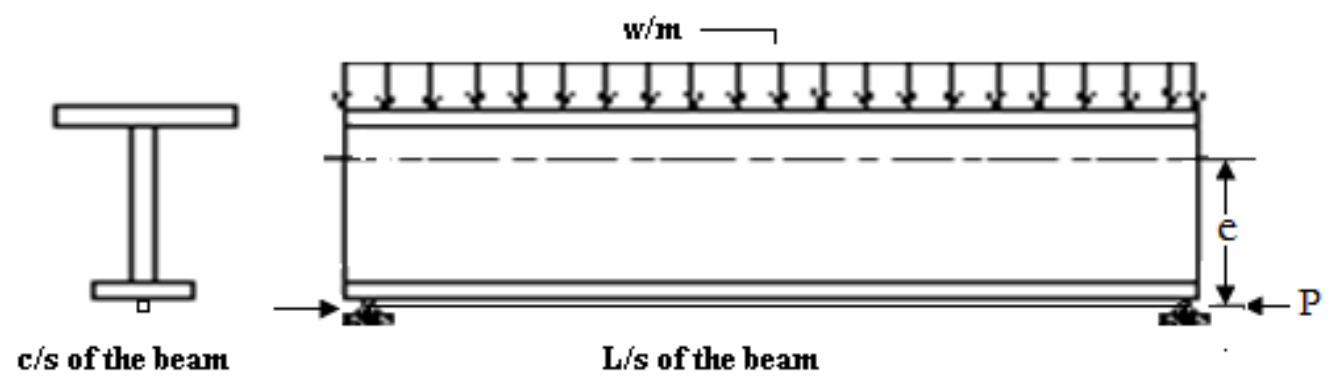

Fig. 1. (b) Tendon placed beyond the cross-section of a loaded beam.

Ideal stress distribution due to prestressing would be one in which top and bottom fiber stresses are equal. If prestressed beams are designed with symmetrical cross section, bottom chord will always remain under-stressed whereas compressive stress in the top chord attains its design value. Theoretically, an infinitely large value of eccentricity would be necessary while prestressing force approaches zero, to obtain the above distribution. In order to utilize material of beam cross section to full capacity, cross section should be designed unsymmetrical, the center of cross section being displaced towards top flange. After prestressing, when an external load is applied to beam, stresses in top and bottom fibers of beam are nearly equal to the design strength of material. Thus, an important feature is that a well-proportioned cross section, results in stress distribution in top and bottom fibers of beam equal to their design strengths. This arrangement has a great deal of promise for economical steel constructions.

\subsection{Beam-Column Behavior of Prestressed Steel Beams}

By placing a straight tendon below a centroid of the beam section, the mid span deflection of a simply supported beam (due to external applied load) will reduce the mid span moment resistant capacity, because of the reduction in the eccentricity of prestressing force. This effect has to be considered during analysis and design of prestressed steel beams. The necessary equations that have been incorporated in the program developed in this paper have been presented by Raju Ponnada and Vipparthy (2014) [38]. They considered a simply supported beam of span '?', Flexural rigidity EI subjected to a total uniformly distributed load of $\mathrm{w}_{\mathrm{tl}} /$ unit length and prestressed by a force ' $\mathrm{P}$ ' at an eccentricity ' $\mathrm{e}$ '. Let the deflection of the beam at a distance ' $\mathrm{x}$ ' from left support is ' $\mathrm{y}$ ' (Fig. 2). By placing the straight tendon below the centroid of the beam section, the mid span deflection of this simple beam (due to the combined action of prestressing force and externally applied load) will reduce the mid span moment resistant capacity, because of the decrease in the 
effective eccentricity of the prestressing force. The authors have considered this effect for all the calculations presented in this paper.

It is to be ensured that the analysis of a prestressed steel I-beam shall allow for the effects of the design loads acting on the structure and its members in their displaced and deformed configuration. These secondorder effects shall be taken into account by considering the change in eccentricity of prestressing force in the deflected beam. In this process, the combined Effect of Prestress and External Load on extreme fiber stresses and Deflection is presented here.

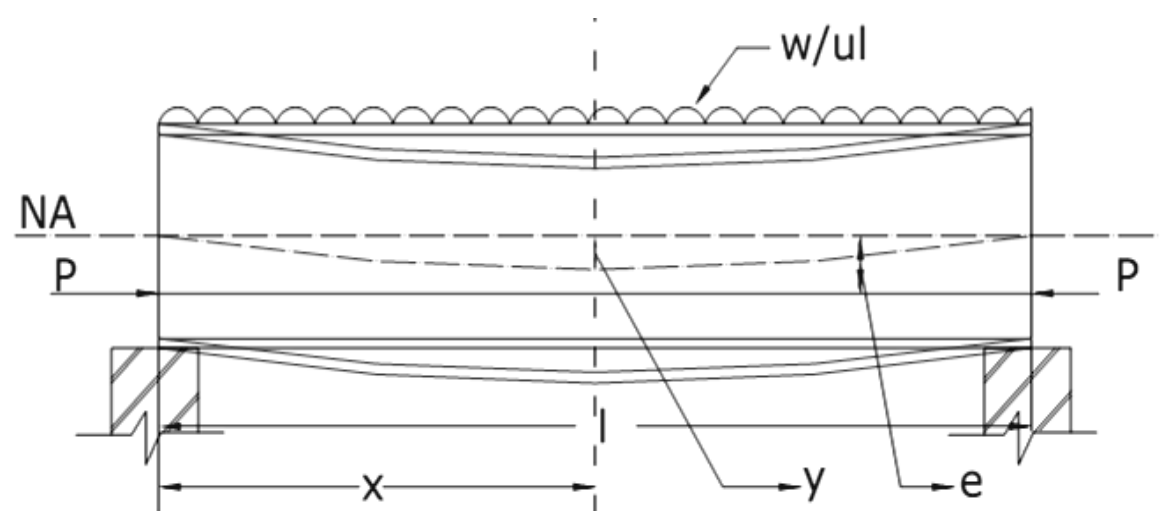

Fig. 2. Deflected shape of the prestressed steel I-beam.

Then, bending moment at any section at a distance of ' $\mathrm{x}$ ' from left support is given by

$$
M_{x}=\left(\frac{w_{t l} \times l \times x}{2}\right)-\left(\frac{w_{t l} \times x^{2}}{2}\right)-P(e-y)
$$

Here,

$\mathrm{P}=$ Magnitude of Prestressing force $(\mathrm{kN})$;

$\mathrm{e}=$ eccentricity $(\mathrm{mm})$

$\mathrm{y}=$ deflection at a section distant $\mathrm{x}$ from left support;

$\mathrm{w}_{\mathrm{tl}}=$ uniformly distributed load acting on the beam (including self weight);

$l=$ span of the beam;

$\mathrm{EI}=$ Flexural rigidity of the material of the beam.

Hence, from the theory of pure bending

$$
E I \frac{d^{2} y}{d x^{2}}=-M_{x}
$$

Solving the differential equation,

$$
y=\left(\frac{w_{t l} \times E \times I_{x}}{P^{2}}-e\right) \times\left\{\frac{\operatorname{Cos}\left(\sqrt{\left.\frac{P}{E \times I_{x}} \times\left(x-\frac{l}{2}\right)\right)}\right.}{\operatorname{Cos}\left(\sqrt{\frac{P}{E \times I_{x}}} \times \frac{l}{2}\right)}-1\right\}+\left(\frac{w_{t l} \times x}{2 \times P}\right) \times(x-l)
$$

This is the generalised expression for finding the deflection of a simply supported eccentrically prestressed beam considering the combined effect of prestress and total load.

Maximum deflection by symmetry occurs at $\mathrm{x}=/ / 2$. Hence, 


$$
y_{\max }=\left(\frac{w_{t l} \times E \times I_{x}}{P^{2}}-e\right) \times\left\{\operatorname{Sec}\left(\sqrt{\frac{P}{E \times I_{x}}} \times \frac{l}{2}\right)-1\right\}-\left(\frac{w_{t l} \times l^{2}}{8 \times P}\right)
$$

Incorporating the beam - column effect, the extreme fiber stresses are calculated. The stress distribution diagrams and the corresponding modified formulae as given below.

Case 1: Application of Concentric pre-stressing force.

The stress distribution for the case of concentric prestressing are not presented here because Ravindra et al. (2008) [31] observed that a minimum eccentricity is required for the beam to be safe in all respects and no significant improvement in the load carrying capacity is achieved by applying even maximum allowable prestressing force concentrically. However, the expressions for the concentric prestressing case could be obtained by substituting " $\mathrm{e}=0$ ", in the expressions presented below.

Case 2: Application of eccentric pre-stressing force

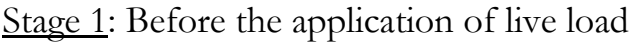
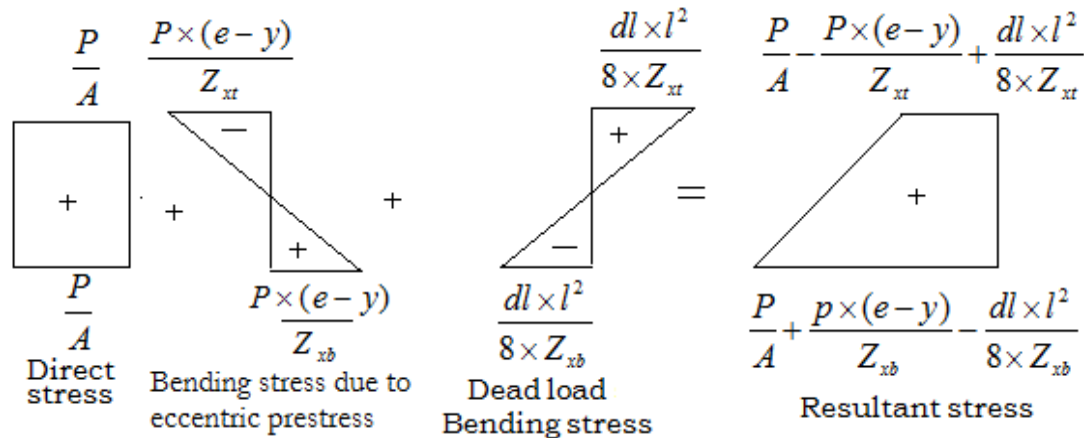

Resultant stress

Fig. 3. (a) Stress distributions due to eccentric pre-stressing and dead load.

Hence extreme fiber stresses at transfer stage are given by:

$$
\begin{gathered}
\text { Stress } @ \text { transfer stage at top fiber }=\sigma_{\mathrm{tnl}}=\frac{P}{A}-\frac{P(e-y)}{Z_{x t}}+\frac{M_{d l}}{Z_{x t}} \\
\text { Stress@ transfer stage at bottom fiber }=\sigma_{b n l}=\frac{P}{A}+\frac{P(e-y)}{Z_{x b}}-\frac{M_{d l}}{Z_{x b}}
\end{gathered}
$$

$\mathrm{M}_{\mathrm{dl}}=$ Bending moment due to self-weight alone;

$\sigma_{\mathrm{bnl}}=$ Stress in bending compression at bottom fiber due to dead load alone $\left(\mathrm{N} / \mathrm{mm}^{2}\right)$;

$\sigma_{\mathrm{tnl}}=$ Stress in bending compression at top fiber due to dead load alone $\left(\mathrm{N} / \mathrm{mm}^{2}\right)$;

$Z_{\mathrm{xt}}=$ Section modulus at top fiber about centroidal $\mathrm{X}-\mathrm{X}$ axes;

$Z_{\mathrm{xb}}=$ Section modulus at bottom fiber about centroidal $\mathrm{X}-\mathrm{X}$ axes. 
Stage 2: After the application of live load

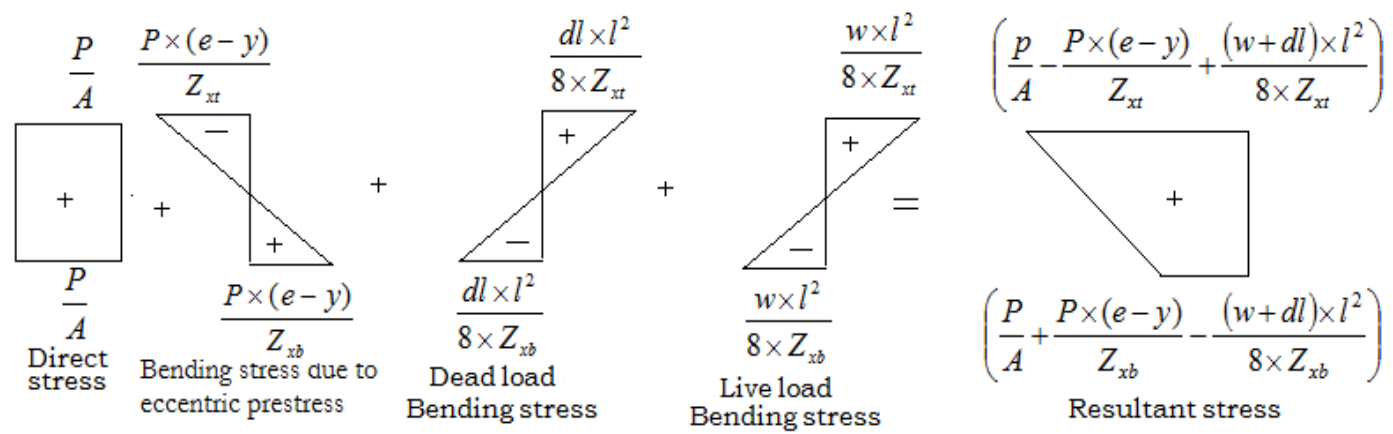

Fig. 3. (b) Stress distributions due to eccentric pre-stressing, dead load and live load.

Hence, extreme fiber stresses at working stage are given by

$$
\begin{aligned}
& \text { Stress } @ \text { working stage at top fiber }=\sigma_{t w}=\frac{P}{A}-\frac{P(e-y)}{Z_{x t}}+\frac{M_{t l}}{Z_{x t}} \\
& \text { Stress } @ \text { working stage at bottom fiber }=\sigma_{b w}=\frac{P}{A}+\frac{P(e-y)}{Z_{x b}}-\frac{M_{t l}}{Z_{x b}}
\end{aligned}
$$

Here,

$\sigma_{\mathrm{bw}}=$ Stress in bending compression at bottom fiber due to dead as well as live load $\left(\mathrm{N} / \mathrm{mm}^{2}\right)$;

$\sigma_{\mathrm{tw}}=$ Stress in bending compression at top fiber due to dead load as well as live load $\left(\mathrm{N} / \mathrm{mm}^{2}\right)$;

$\mathrm{M}_{\mathrm{tl}}=$ Bending moment due to total load (self-weight + live load).

Here we observe that the dead and live loads induce tensile stresses towards the soffit. Further the compressive stress at the top fiber is substantially reduced. To elevate this, the pre-stressing tendon is placed eccentrically below the neutral axes. This approach induces tensile stresses at the top fiber and compressive stresses at the bottom fiber through an eccentric moment of ' $\mathrm{P} \times \mathrm{e}$ '. In either case, it is to be ensured that the stresses calculated in the two stages should be less than allowable bending stress. The above relationships show that the presence of the pre-stressing compressive force reduces the tensile flexural stress either by eliminating tension and inducing some compression or by permitting some tensile stress within permissible limits. Identifying the "prestressing force" that satisfies the internal equilibrium (Total Compression $=$ Total tension), Moment of resistance equation while ensuring that the stresses at transfer and working at extreme fibers are within permissible limits is a nonlinear multi-variable optimization problem.

\subsection{Losses Encountered in Prestressed Steel Beams}

The prestressing force at any point in the structures is always less than the force measured at the jack during stressing. The difference between the effective prestressing force and jacking force is called the loss of prestress. Determination of exact or at least a reasonably approximate magnitude of loss of prestress and compensation of it is important in the design of prestressed structures. However, prestressed steel beams are a special case. In this paper, losses have not been considered for all calculation purposes. A detailed explanation of the reasons for not considering losses is presented in this section.

\subsubsection{Loss of prestress}

Little literature is available on estimation of losses in pre-stressed steel members. Belletti and Gasper (2010) [32] opined that stress losses in tendons are not considered because friction losses are negligible for un- 
bonded tendons and relaxation losses are negligible. According to Ravindra Vipparthy and Markandeya Raju Ponnada (2012) [34], "The magnitude of friction loss due to length effect, loss of prestress due to elastic deformation of beam, loss of prestress due to anchorage slip and loss of prestress due to bending of the beam are significant" and "If the technique of re-tensioning is not employed, then the loss of stress due to relaxation of prestressing steel is significant".

\subsubsection{Loss of prestress - compensation}

It is known that the losses generally encountered in pre-stressed concrete members are about $25-35 \%$ while the same in pre-stress steel members is approximately $5-10 \%$. Although the loss of stress in pre-stressed steel member is small the uncertainty involved in estimation is high. It is known that underestimation of losses leads to reduced net Prestressing force, thus not using the system to its full capacity. Overestimation of losses leads to high Prestressing force causing excessive camber and tensile stresses in concrete, also buckling in steel. An exact determination of the PS losses is not feasible all the time. In some special cases it is reasonable to consider the lump-sum loss estimates. Although Ravindra Vipparthy and Markandeya Raju Ponnada (2012) [34] formulates a procedure to find the reasonable estimate of total loss, it's reliability is yet to be established as it is not an experimental work. Also it is not to appropriate to consider thumb rules for losses. However, researchers and engineers have been considering only an approximate lump sum estimate of the losses (9 to 12\%). Even if exact losses can be determined, they have to be compensated to prevent their effect on the load carrying capacity and service load behaviour such as deflection and crack width.

There are two ways of compensating loss of pre-stress in tendons of pre-stressed members.

1) Over stressing the tendon to the tune of estimated loss that may occur in the tendon

2) Re-stressing the tendon from time to time to the tune of loss that has occurred in it.

While the first method is suitable for pre-stressed concrete it is not suitable for pre-stressed steel beams. This is because, in pre-stressed steel beams the maximum pre-stressing force that is required for maximum increase in the load carrying capacity in the member is determined considering safety against compression flange buckling, web buckling, lateral torsional buckling in addition to the common failure modes encountered (flexure, shear, combined axial and bending, deflection, etc.)

By overstressing beyond max possible pre-stressing force there is every chance of the member failing in one of these modes. If we stress the tendon to maximum possible prestressing force, then the load carrying capacity due to prestressing will be reduced and the section is not utilised to its full capacity. Hence, the basic objective of optimisation is not achieved.

In certain structures like pre-stressed steel structures, it may be more practical and feasible to re-stress before and during working stage from time to time (for reasons other than relaxation) to compensate for loss of prestress rather than overstressing the tendons at transfer stage. Tests have shown that the relaxation loss is considerably less after re-stressing than the loss that occurs after the first stressing.

It is important to note that re-stressing is an appropriate method for best performance of the prestressed steel beams because it overcomes the effects of overestimated/underestimated losses or in general losses.

However, it is not feasible for pre-tensioned concrete and post-tensioned concrete (with bonded or grouted tendons) because the additional stress applied to tendon after losses have occurred will lead to loss of bond between tendon and concrete there by preventing effective transfer of pre-stress from tendon to member.

\subsubsection{Re-stressing of tendons}

To re-stress the tendon to its initial stress state, the loss of stress or current state of stress in the tendon has to be determined. It will be worthwhile to note that there is no direct method available to measure loss of prestress. However, it can be ascertained by knowing the changes in stress levels in pre-stressing cables. The change in stress level can be known by periodical measurement of the same. The force in pre-stressing steel can be measured by using Vibrating Wire (VW) Load Cells or Vibrating Wire (VW) Strain Gauges. There are also many NDT methods exclusively for stress measurement in pre-stressing steel strands. For example,

X-Ray Diffraction for Direct Stress Measurements: This technique provides quantifiable results, is nondestructive, and provides a measure of total stresses (applied plus residual stresses). 
Ultrasonic Defect Detection: Ultrasonic waves can travel relatively long distances along pre-stressing strands when those strands are suspended in air. However, when a strand is embedded in concrete, signal attenuation limits the distance of wave penetration to one or two meters. Aggregate sizes that are comparable to the wavelength of the ultrasonic signal result in large-scale scattering or "grain noise."

In summary, the most practicable and optimum method of designing a prestressed steel beam is by ignoring losses while designing. However, the prestress is to be measured (using suitable NDT techniques) and compensated by re-stressing from time to time as external unbounded prestressing is adopted. Hence, in this paper, the loss of prestress effect in the author's computer aided analysis (or used a reasonable approximate value in the program) is not included as it is assumed that it is compensated form time to time.

Even if loss of prestress is considered, the effect will be in terms of only the absolute magnitudes of the parameters under study (because only magnitude of prestress will change). The variation of parameters will not change.

\section{Objective, Scope and Methodology}

\subsection{Objective and Scope}

The objective of this work is to determine the optimum dimensions of a simply supported, laterally unsupported, prestressed steel I-beam that can take a given load over a given span.

The safety of various sets of dimensions ranging from the minimum dimensions of I-section in ISHand Book-1 to their maximum dimensions for different prestressing forces and eccentricities were checked and the set with minimum cross sectional area was chosen. A ' $\mathrm{C}$ ' program has been developed for checking the safety and suitability of a chosen pre-stressed steel I-section. All possible cross-sections with in a range of dimensions are checked for their appropriateness on a trial and error basis and the dimensions with minimum cross sectional area are finally chosen. Reference dimensions are chosen from IS Hand Book 1 so as to ensure a well-proportioned cross-section. The study is limited to $6 \mathrm{~m}, 8 \mathrm{~m}, 10 \mathrm{~m}$ and $12 \mathrm{~m}$ span beams.

\subsection{Methodology}

In addition to the assumptions in the theory of pure bending, thin walled beam theory and working stress design of steel and prestressed concrete structures, it is assumed that there is no loss of prestress and there is no lateral buckling under the combined action of prestressing force and the external loads. An unsymmetrical steel I- beam (Fig. 1(a)) prestressed with a constant eccentric prestressing force acting at a distance ' $\mathrm{e}$ ' from neutral-axis of beam. A set of dimensions beginning with the smallest I-section in IS: Handbook No. 1 [44] is chosen. The maximum shear stress, the dead load and live load bending moments are calculated. The bending stresses in the extreme fibers at mid span section, the shear at neutral axis of the support section, the net deflection at transfer and at working are determined and checked against their permissible values. The check for the ratio of "thickness to depth of web" ratio of the I-section is performed to avoid the possibility of buckling. The check for crippling is also performed. The set of dimensions for which the stresses at all stages are with in permissible limits are addressed as optimum dimensions. The procedure is repeated with small increment in dimensions if any one of the prescribed checks is not satisfied.

\subsection{Algorithm for Optimum dimensioning of Prestressed Unsymmetrical Steel I-beam}

A detailed explanation of the formulation of the problem and solution methodology is presented in the following algorithm. The algorithm has been developed based on provisions drafted in IS 8001984 [45].

Step-1: Given data

The magnitudes of live load carrying capacity 'Lcc' required and span $(l)$ are noted.

Step-2: Initialize the values of variables 
The minimum values of I-section are initialized to the dimensions as given below.

$$
d=140, w_{t f}=50, t_{t f}=4, t_{w}=2, t_{b f}=4, w_{b f}=50 .
$$

Here,

$\mathrm{d}=$ depth of web;

$\mathrm{w}_{\mathrm{tf}}=$ width of top flange (for asymmetrical I-sections);

$\mathrm{t}_{\mathrm{tf}}=$ thickness of top flange (for asymmetrical I-sections);

$\mathrm{t}_{\mathrm{w}}=$ thickness of web (for asymmetrical I-sections);

$\mathrm{t}_{\mathrm{bf}}=$ thickness of bottom flange (for asymmetrical I-sections);

$\mathrm{w}_{\mathrm{bf}}=$ width of bottom flange (for asymmetrical I-sections).

Step-3: Calculation of geometric parameters and maximum bending moment

Calculate the magnitudes of $A, y_{t}, y_{b}, I_{x x}, Z_{x t}, Z_{x b}, d l, M_{d l}, M_{t l}, I_{y y}, r_{y}$.

Here,

$\mathrm{y}_{\mathrm{t}}=$ distance of the centroidal $\mathrm{X}-\mathrm{X}$ axes from top most fiber;

$\mathrm{yb}_{\mathrm{b}}=$ distance of the centroidal $\mathrm{X}-\mathrm{X}$ axes from bottom most fiber;

$\mathrm{I}_{\mathrm{xx}}=$ Moment of Inertia about centroidal X-X axes $\left(\mathrm{mm}^{4}\right)$;

$\mathrm{I}_{\mathrm{yy}}=$ Moment of Inertia about centroidal $\mathrm{Y}-\mathrm{Y}$ axes $\left(\mathrm{mm}^{4}\right)$;

$\mathrm{A}=$ Area of cross-section of the beam;

$\mathrm{dl}=$ dead load or self-weight of the beam;

$r_{y}=$ radius of gyration about centroidal $Y-Y$ axes.

Step-4: Calculation of $\sigma_{c b c}$ (permissible bending compressive stress as applicable for laterally unsupported beams)

For laterally unsupported length, the allowable bending stresses are less than ' $0.6 \mathrm{fy}$ ' to prevent the lateral torsional buckling failure. The specification that the authors used to compute allowable bending stress are adopted from Clause 6.2.4 of IS 8001984 [45]. This clause ensures that lateral torsional buckling failure does not occur prior to the attainment of bending compressive stress. Another assumption is that the beam is assumed to be laterally unsupported but there is no lateral buckling under the combined action of prestressing force and the external loads as shorter spans are considered (only up to $12 \mathrm{~m}$ ). Further, it is also assumed that stiffeners are designed and provided it lateral tensional buckling occurs. Hence, the beam will be checked only for buckling only under the combined action of dead load and live load.

The magnitudes of $k_{1}, k_{2}, c_{1}, c_{2}, Y, X$ are calculated.

Here, $k_{1}=$ a Coefficient to allow for reduction in thickness or breadth of flanges between points of effective lateral restraint and depends on the ratio of the total area of both flanges at the point of least bending moment to the corresponding area at the point of greatest bending moment between such points of restraint. Values of $\mathrm{k}_{1}$ are given in Table 6.3 of IS 8001984 [45].

$k_{2}=$ a coefficient to allow for the inequality of flanges, and depends on $\omega$, the ratio of the moment of inertia of the compression flange alone to that of the sum of the moments of inertia of the flanges, each calculated about its own axes parallel to the $y-y$ axis of the girder, at the point of maximum bending moment (Values of $\mathrm{k}_{2}$ are given in Table 6.4 of IS 8001984 [45]).

$c_{1}, c_{2}=$ the lesser and greater distances from the section neutral axis to the extreme fibers respectively.

$$
\begin{gathered}
Y=\frac{26.5 \times 10^{5}}{\left(l / r_{y}\right)^{2}} \mathrm{MPa}, \\
X=Y \sqrt{1+\frac{1}{20}\left(\frac{l \times T}{r_{y} \times D}\right)^{2}} \mathrm{MPa} .
\end{gathered}
$$


By using the values

$$
k_{1}, k_{2}, c_{1}, c_{2}, Y, X
$$

Calculate the

$$
\sigma_{c b c}=k_{1}\left(X+k_{2} Y\right) \frac{c_{2}}{c_{1}}
$$

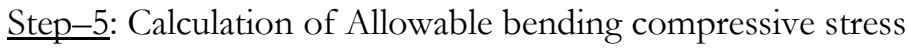

$\sigma_{c s}=$ Allowable bending compressive stress $\left(\mathrm{N} / \mathrm{mm}^{2}\right)$, from Clause 6.2.3 of IS 8001984 [45]

$$
\sigma_{c s}=0.66 \times \frac{\sigma_{c b c} \times f_{y}}{\left.\left[\left(\sigma_{c b c}\right)^{n}+\left(f_{y}\right)\right]^{n}\right]^{1 / n}}
$$

Here,

$\sigma_{c b c}=$ permissible bending compressive stress as applicable for laterally unsupported beams;

$f_{y}=$ yield stress of the steel assumed as $250 \mathrm{~N} / \mathrm{mm}^{2}$ and $\mathrm{n}=\mathrm{a}$ factor assumed as 1.4.

Here, $\sigma_{c b c}=<0.6 \mathrm{f}_{\mathrm{y}}$ so as to avoid lateral torsional buckling of laterally unsupported beams. According to Appendix E of IS 8001984 [45], the calculations presented in Step 4 is based on Timoshenko and Gere (1961) [46], Bleich (1952) [47], Johnston (1966) [48], Galambos (1968) [49], Column Research Committee of Japan (1971) [50], Allen and Bulson (1980) [51], ASCE (1977) [52], Lee (1960) [53], Trahair (1966) [54], Trahair (1966) [55], Trahair (1968) [56], and Leigh et al. (1971) [57].

Step-6: Check the condition ' $y_{t}$ ' with ' $t_{t f}$ ' to get the values of $A_{1}, y_{1}, t_{1}$.

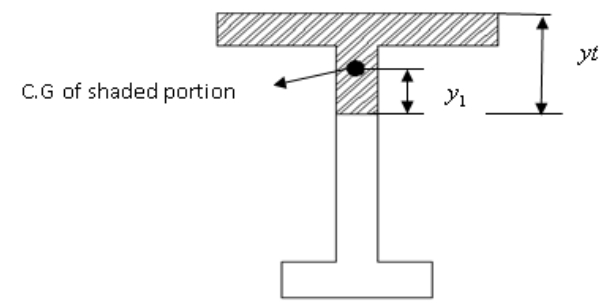

Fig. 4. Compression zone of prestressed unsymmetrical I-beam.

Step-7: Initialize the value FF $=0$ and ER $=0$.

Here,

$$
\begin{gathered}
\mathrm{FF}=\text { Force factor }=\mathrm{P} /\left(\sigma_{c b c} \times \mathrm{A}\right) \\
\mathrm{ER}=\text { Eccentricity ratio }=\mathrm{e} / \mathrm{D} \\
\mathrm{D}=\text { Total depth of the beam. }
\end{gathered}
$$

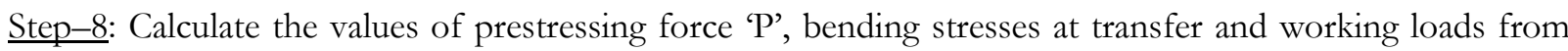
Eq. (5), (6), (7) and (8) (at top and bottom fibers), and deflection (def ) from Eq. (4) as per Raju Ponnada and Vipparthy (2014) [38].

Step-9: Check the conditions (Permissible stresses and deflection (Span (mm)/240) 
The shear at neutral axis of the support section is determined and checked against its permissible value.

Maximum shear stress induced in member:

$$
\tau_{c a l}=\frac{V \times A_{1} \times Y_{1}}{I_{x x} \times t_{w}}<(0.45 \times f y)
$$

Crippling stress is calculated and checked as follows:

$$
C=\frac{V}{(300+h \times \sqrt{3}) \times t_{w}}<\left(0.75 \times f_{y} \text { for I-Section }\right)
$$

The check for the ratio of "thickness to depth of web" ratio of the I-section is performed to avoid the possibility of buckling. The check for combined bending \& shears and combined bending \& compression are also performed as per Clause 7.1.1 and Clause 7.1.4 of IS 8001984 [45].

Step-10: Calculate the load carrying capacity Lcc

$$
L c c=\left(\frac{\sigma_{c s} \times Z_{x t} \times 8}{l^{2}}\right)-\left(\frac{P}{A}-\frac{P \times(e-y)}{Z_{x t}}\right) \times\left(\frac{Z_{x t} \times 8}{l^{2}}\right)-d l
$$

Step-11: Note the values of dimensions, prestressing force and eccentricity and increment FF and ER

Increase FF by 0.03 (until FF = 1) while limiting the maximum prestressing force that can be applied on a steel beam is by

$$
\mathrm{P}=\left(\frac{\sigma_{c s} \times A \times Z_{x b}}{A \times e+Z_{x b}}\right)
$$

and ER by 0.03 until

$$
E R=\frac{y_{b}-t_{b f}}{D}
$$

Equations (17), (18) and (19) are adopted from Ravindra et al. (2008) [31].

Here, $\mathrm{D}=$ Total depth of the beam (mm).

Step-11: Repeat Step-9 to Step-12 by increment the dimensions of the I-section up to a maximum of

$\mathrm{D}=600, \mathrm{w}_{\mathrm{tf}}=\mathrm{w}_{\mathrm{bf}}=250, \mathrm{t}_{\mathrm{w}}=\mathrm{t}_{\mathrm{tf}}=\mathrm{t}_{\mathrm{bf}}=24$

Step-12: Repeat the Step-1 to Step-11 and ascertain the dimensions, P and e corresponding to the minimum cross sectional area and Lcc required. The set of dimensions for which the stresses at all stages are within permissible limits are addressed as optimum dimensions.

\subsection{Computer Aided Analysis of Prestressed Steel I-Beam}

A program is developed for the procedure discussed in Section 1 and 3. It gives the optimum dimensions of an unsymmetrical prestressed steel I- beam that can carry a given load over a given span. The dimensions are limited to the maximum dimensions of I-sections in IS-Hand Book No-1 [44] so as to ensure a well proportional cross-section. The loss of prestress in the prestressing tendon is neglected. The $f_{y}$ of the 
material of the I-section is taken as $250 \mathrm{MPa}$. A straight tendon configuration over the whole span is considered for study.

\subsection{Limitations of Present Study}

1) The dimensions are limited to the maximum dimensions of I-sections in IS-Hand book No-1 [44] so as to ensure a well proportional cross-section.

2) The span of the beam is limited to $12 \mathrm{~m}$.

3) The load carrying capacity is limited to $100 \mathrm{kN} / \mathrm{m}$ in multiples of $10 \mathrm{kN} / \mathrm{m}$.

\section{Results and Discussion}

\subsection{Results}

The program developed by the authors was executed for spans of $6 \mathrm{~m}, 8 \mathrm{~m}, 10 \mathrm{~m}$ and $12 \mathrm{~m}$ and Load carrying capacities if $10 \mathrm{kN} / \mathrm{m}$ to $100 \mathrm{kN} / \mathrm{m}$. Non-dimensional parameters in terms of dimensions of the Isection and extreme fiber stresses were determined and presented in this Section 5.1. The following design tables were obtained by executing the program.

Table 1. Non dimensional parameters.

\begin{tabular}{|c|c|c|c|c|c|c|c|c|c|}
\hline$\overline{\text { Span }}$ & Lcc & $\mathrm{dl}$ & wl & $\mathbf{P}$ & & $\mathrm{e}$ & & pLcc & pDef \\
\hline $\mathrm{m}$ & $\mathrm{kN} / \mathrm{m}$ & $\mathrm{kN} / \mathrm{m}$ & $\mathrm{kN} / \mathrm{m}$ & $\mathrm{kN}$ & FF & $\mathrm{mm}$ & ER & $\%$ & $\%$ \\
\hline \multirow{10}{*}{6} & 10 & 0.4 & 4.9 & 84 & 0.24 & 180 & 0.6 & 102.9 & $\begin{array}{l}-37.3 \\
\end{array}$ \\
\hline & 20 & 0.5 & 14.3 & 158 & 0.21 & 144 & 0.48 & 39.7 & -27.7 \\
\hline & 30 & 0.7 & 25.1 & 25 & 0.03 & 135 & 0.3 & 19.5 & -2.8 \\
\hline & 40.1 & 0.7 & 25.9 & 175 & 0.21 & 268 & 0.51 & 54.9 & -30.2 \\
\hline & 50.1 & 0.8 & 26.6 & 286 & 0.27 & 256 & 0.57 & 87.9 & -37.6 \\
\hline & 60 & 0.9 & 36.4 & 33 & 0.03 & 216 & 0.36 & 65.1 & -3 \\
\hline & 70 & 1 & 58 & 82 & 0.06 & 306 & 0.51 & 20.7 & -9.2 \\
\hline & 80.1 & 1.1 & 71.9 & 94 & 0.06 & 270 & 0.45 & 11.4 & -8.2 \\
\hline & 90 & 1.2 & 59 & 274 & 0.18 & 324 & 0.54 & 52.7 & -25.6 \\
\hline & 100.1 & 1.3 & 99.5 & 68 & 0.03 & 236 & 0.45 & 0.5 & -4.1 \\
\hline \multirow{5}{*}{8} & 10 & 0.6 & 8.4 & 23 & 0.03 & 27 & 0.1 & 19.5 & -0.3 \\
\hline & 20 & 0.8 & 14.1 & 84 & 0.12 & 324 & 0.5 & 41.8 & -19.2 \\
\hline & 30 & 1 & 23.7 & 35 & 0.03 & 252 & 0.5 & 26.6 & -4.1 \\
\hline & 40 & 1.1 & 27.1 & 38 & 0.03 & 198 & 0.3 & 47.7 & -2.6 \\
\hline & 50 & 1.8 & 42.8 & 246 & 0.12 & 252 & 0.4 & 16.8 & -17.5 \\
\hline \multirow{2}{*}{10} & 10 & 0.8 & 9.9 & 30 & 0.03 & 34 & 0.1 & 0.9 & -0.4 \\
\hline & 20 & 1.1 & 12.3 & 226 & 0.21 & 299 & 0.6 & 63 & -29.6 \\
\hline 12 & 10 & 1 & 6.8 & 256 & 0.3 & 268 & 0.5 & 49 & -39.6 \\
\hline
\end{tabular}

In Table 1,

Lcc $=$ Live load carrying capacity of the prestressed beam, beam,

pLcc $=\%$ increase in load carrying capacity of the prestressed beam with respect to un-prestressed

$\mathrm{pDef}=$ percentage decrease in deflection due to prestressing. 
Table 2. Dimensions of I-section.

\begin{tabular}{|c|c|c|c|c|c|c|c|c|c|}
\hline Span & Lcc & $\mathbf{w}_{\mathrm{tf}}$ & $\mathbf{w}_{\mathrm{bf}}$ & $t_{t f}$ & $t_{b f}$ & $t_{w}$ & D & $y_{t}$ & $\mathbf{y}_{b}$ \\
\hline $\mathbf{M}$ & $\mathrm{kN} / \mathrm{m}$ & $\mathrm{mm}$ & $\mathrm{mm}$ & $\mathrm{mm}$ & $\mathrm{mm}$ & $\mathrm{mm}$ & $\mathrm{Mm}$ & $\mathrm{mm}$ & $\mathrm{mm}$ \\
\hline \multirow{10}{*}{6} & 10 & 260 & 85 & 8 & 8 & 8 & 284 & 109.4 & 190.6 \\
\hline & 20 & 120 & 225 & 26 & 8 & 8 & 266 & 129.4 & 170.6 \\
\hline & 30 & 120 & 260 & 26 & 8 & 8 & 416 & 204.9 & 245.1 \\
\hline & 40 & 260 & 225 & 14 & 8 & 8 & 503 & 214.7 & 310.3 \\
\hline & 50 & 260 & 260 & 20 & 8 & 8 & 422 & 165.1 & 284.9 \\
\hline & 60 & 260 & 260 & 20 & 8 & 8 & 572 & 227.1 & 372.9 \\
\hline & 70 & 190 & 260 & 26 & 14 & 8 & 560 & 275.2 & 324.8 \\
\hline & 80 & 260 & 225 & 20 & 20 & 8 & 560 & 285.7 & 314.3 \\
\hline & 90 & 260 & 190 & 26 & 20 & 8 & 554 & 245 & 355 \\
\hline & 100 & 260 & 260 & 26 & 26 & 8 & 473 & 262.5 & 262.5 \\
\hline \multirow{5}{*}{8} & 10 & 120 & 260 & 26 & 8 & 8 & 266 & 136 & 164 \\
\hline & 20 & 260 & 260 & 14 & 8 & 8 & 578 & 258 & 342 \\
\hline & 30 & 260 & 260 & 20 & 14 & 8 & 491 & 233 & 292 \\
\hline & 40 & 260 & 260 & 26 & 20 & 20 & 554 & 283 & 317 \\
\hline & 50 & 260 & 260 & 26 & 14 & 8 & 560 & 243 & 357 \\
\hline \multirow{2}{*}{10} & 10 & 155 & 260 & 26 & 14 & 8 & 335 & 185 & 190 \\
\hline & 20 & 260 & 260 & 26 & 14 & 8 & 485 & 211 & 314 \\
\hline 12 & 10 & 225 & 260 & 26 & 14 & 8 & 485 & 225 & 300 \\
\hline
\end{tabular}

In Table 2,

$\mathrm{d}=$ depth of web.

Table 3. Non dimensional parameters (Dimensions) of I-section.

\begin{tabular}{|c|c|c|c|c|c|c|c|c|}
\hline$\frac{\text { Span }}{\mathbf{m}}$ & $\frac{\mathrm{Lcc}}{\mathrm{kN} / \mathrm{m}}$ & $\frac{A}{\left(\mathrm{~cm}^{2}\right)}$ & A/WA & A/TFA & A/BFA & TFA/BFA & $y_{t} / y_{b}$ & FA/WA \\
\hline \multirow{10}{*}{6} & 10 & 50.3 & 2.21 & 2.42 & 7.4 & 3.06 & 0.57 & 1.21 \\
\hline & 20 & 70.5 & 3.31 & 2.26 & 3.92 & 1.73 & 0.76 & 2.31 \\
\hline & 30 & 85.3 & 2.56 & 2.73 & 4.1 & 1.5 & 0.84 & 1.56 \\
\hline & 40 & 94.6 & 2.35 & 2.6 & 5.26 & 2.02 & 0.69 & 1.35 \\
\hline & 50 & 106.6 & 3.16 & 2.05 & 5.13 & 2.5 & 0.58 & 2.16 \\
\hline & 60 & 118.6 & 2.59 & 2.28 & 5.7 & 2.5 & 0.61 & 1.59 \\
\hline & 70 & 130.6 & 2.92 & 2.64 & 3.59 & 1.36 & 0.85 & 1.92 \\
\hline & 80 & 141.8 & 3.17 & 2.73 & 3.15 & 1.16 & 0.91 & 2.17 \\
\hline & 90 & 149.9 & 3.38 & 2.22 & 3.94 & 1.78 & 0.69 & 2.38 \\
\hline & 100 & 173 & 4.57 & 2.56 & 2.56 & 1 & 1 & 3.57 \\
\hline \multirow{5}{*}{8} & 10 & 73.3 & 3.44 & 2.35 & 3.52 & 1.5 & 0.83 & 2.44 \\
\hline & 20 & 103 & 2.24 & 2.84 & 4.97 & 1.75 & 0.75 & 1.24 \\
\hline & 30 & 128 & 3.25 & 2.46 & 3.51 & 1.43 & 0.8 & 2.25 \\
\hline & 40 & 149 & 1.34 & 2.2 & 2.86 & 1.3 & 0.89 & 1.08 \\
\hline & 50 & 230 & 5.14 & 3.41 & 6.33 & 1.86 & 0.68 & 2.32 \\
\hline \multirow{2}{*}{10} & 10 & 104 & 3.86 & 2.57 & 2.84 & 1.11 & 0.97 & 2.86 \\
\hline & 20 & 143 & 3.68 & 2.11 & 3.92 & 1.86 & 0.67 & 2.68 \\
\hline 12 & 10 & 134 & 3.45 & 2.29 & 3.67 & 1.61 & 0.75 & 2.45 \\
\hline
\end{tabular}

In Table 3,

$\mathrm{WA}=$ area of the web;

TFA $=$ area of the compression flange or top flange;

$\mathrm{BFA}=$ area of the tension flange or bottom flange; 
$\mathrm{FA}=$ sum of the areas of top and bottom flanges or total flange area.

Table 4. Stress at transfer and working loads.

\begin{tabular}{|c|c|c|c|c|c|c|c|}
\hline Span & Lcc & $\sigma_{\mathrm{cs}}$ & $\sigma_{\mathrm{ts}}$ & $\sigma_{\mathrm{bw}}$ & $\sigma_{\mathrm{tw}}$ & $\sigma_{\text {bnl }}$ & $\sigma_{\mathrm{tnl}}$ \\
\hline $\mathrm{m}$ & $\mathrm{kN} / \mathrm{m}$ & $\mathrm{MPa}$ & $\mathbf{M P a}$ & $\mathrm{MPa}$ & $\mathbf{M P a}$ & $\mathrm{MPa}$ & MPa \\
\hline \multirow{10}{*}{6} & 10 & 69.5 & -165 & -75.4 & 69.5 & 55.4 & -5.5 \\
\hline & 20 & 106.9 & -165 & \begin{tabular}{|c|}
-88.9 \\
\end{tabular} & 106.9 & 54.9 & -2.2 \\
\hline & 30 & 99.1 & -165 & -112.1 & 999.1 & 3.4 & 2.6 \\
\hline & 40.1 & 88.2 & -165 & -82.2 & 88.2 & 50.7 & -3.7 \\
\hline & 50.1 & 99.4 & -165 & -98.3 & 99.4 & 82.9 & -5.6 \\
\hline & 60 & 91.8 & -165 & -143.5 & 91.8 & 4.4 & 1.8 \\
\hline & 70 & 104 & -165 & -109.2 & 104 & 14.2 & -0.5 \\
\hline & 80.1 & 111 & -165 & -108.1 & 111 & 13.6 & 0.3 \\
\hline & 90 & 101.7 & -165 & -102.5 & 101.7 & 49.7 & -3.4 \\
\hline & 100.1 & 130.5 & -165 & -122.7 & 130.5 & 6.8 & 1 \\
\hline \multirow{5}{*}{8} & 10 & 102.8 & -165 & -118 & 103 & -2.5 & 7.7 \\
\hline & 20 & 67.4 & -165 & -70.7 & 67.4 & 20 & -0.7 \\
\hline & 30 & 90.3 & -165 & -107 & 90.3 & 3.1 & 2.4 \\
\hline & 40 & 85.9 & -165 & -120 & 85.9 & 2 & 3 \\
\hline & 50 & 89 & -165 & -77.3 & 89 & 23 & 0 \\
\hline \multirow{2}{*}{10} & 10 & 95.6 & -165 & -93 & 96 & -3.5 & 9.1 \\
\hline & 20 & 75.4 & -165 & -73 & 75 & 40 & -0.5 \\
\hline 12 & 10 & 63.9 & -165 & -41 & 64 & 42 & 2.1 \\
\hline
\end{tabular}

In Table 4,

$\sigma_{\mathrm{ts}}=$ Allowable bending tensile stress $\left(\mathrm{N} / \mathrm{mm}^{2}\right)$.

Table 5. Non dimensional stresses at transfer and working loads.

\begin{tabular}{|c|c|c|c|c|c|c|c|}
\hline Span (m) & Lcc (kN/m) & $\overline{\text { DSRB }}$ & $\overline{\text { DSRT }}$ & TSRB & TSRT & TSR & WSR \\
\hline \multirow{10}{*}{6} & 10 & 0.46 & 1 & 0.8 & 0.03 & -0.1 & -0.92 \\
\hline & 20 & 0.54 & 1 & 0.51 & 0.01 & -0.04 & -1.2 \\
\hline & 30 & 0.68 & 1 & 0.03 & -0.02 & 0.76 & -0.88 \\
\hline & 40.1 & 0.5 & 1 & 0.57 & 0.02 & -0.07 & -1.07 \\
\hline & 50.1 & 0.6 & 1 & 0.83 & 0.03 & -0.07 & -1.07 \\
\hline & 60 & 0.87 & 1 & 0.05 & -0.01 & 0.41 & -0.64 \\
\hline & 70 & 0.66 & 1 & 0.14 & 0 & -0.04 & -0.95 \\
\hline & 80.1 & 0.66 & 1 & 0.12 & 0 & 0.02 & -1.03 \\
\hline & 90 & 0.62 & 1 & 0.49 & 0.02 & -0.07 & -0.99 \\
\hline & 100.1 & 0.74 & 1 & 0.05 & -0.01 & 0.15 & -1.06 \\
\hline \multirow{5}{*}{8} & 10 & 0.72 & 1 & -0.02 . & 0.05 & -3.08 & -0.87 \\
\hline & 20 & 0.43 & 1 & 0.3 & 0 & -0.04 & -0.95 \\
\hline & 30 & 0.65 & 1 & 0.03 & -0.01 & 0.77 & -0.85 \\
\hline & 40 & 0.73 & 1 & 0.02 & -0.02 & 1.5 & -0.72 \\
\hline & 50 & 0.47 & 1 & 0.26 & 0 & 0 & -1.15 \\
\hline \multirow{2}{*}{10} & 10 & 0.56 & 1 & -0.04 & -0.06 & -2.6 & -1.03 \\
\hline & 20 & 0.44 & 1 & 0.53 & 0 & -0.01 & -1.04 \\
\hline 12 & 10 & 0.25 & 1 & 0.66 & -0.01 & 0.05 & -1.57 \\
\hline
\end{tabular}

In Table 5,

DSRB $=$ Design Stress Ratio at bottom fiber for working loads $=\sigma_{b w} / \sigma_{t s}$ 
DSRT $=$ Design Stress Ratio at top fiber for working loads $=\sigma_{t w} / \sigma_{c s}$

TSRB $=$ Design Stress Ratio at bottom fiber at transfer $=\sigma_{b n l} / \sigma_{c s}$

TSRT $=$ Design Stress Ratio at top fiber at transfer $=\sigma_{t n l} / \sigma_{t s}$

TSR $=$ Stress ratio at transfer $=\sigma_{t n l} / \sigma_{b n l}$ and WSR $=$ Stress ratio at working loads $=\sigma_{t w} / \sigma_{b w}$

In general, by adopting an unsymmetrical I-section, the beam can be made stronger in compression and hence the maximum allowable prestress that can be applied can also be increased. Further by adopting an unsymmetrical I-section, the Neutral axis of the beam is shifted towards top fiber. Hence the range of eccentricity that can be conveniently and safely adopted is increased. By increasing the magnitude of prestress and eccentricity, a higher load carrying capacity can be achieved. However, the parameters corresponding minimum cross-sectional area required for a particular span and Lcc depend on a variety of factors. Hence, each set of parameters is unique corresponding to a particular Lcc and span. The variation among two or more of these factors cannot be studied because when two parameters are being compared, the remaining parameters should be kept constant. Therefore, the tables given in Section 5.1 serve the purpose of a design table from which the parameters can be chosen for a particular Lcc and span.

\subsection{Variation of maximum Lcc with Span}

From Tables 1, it is observed that maximum possible Lcc for spans under consideration are as follows.

Table 6. Variation of span with maximum possible Lcc.

\begin{tabular}{cc}
\hline Span $(\mathbf{m})$ & Maximum possible Lcc $(\mathrm{kN} / \mathbf{m})$ \\
\hline 6 & 100 \\
\hline 8 & 50 \\
\hline 10 & 20 \\
\hline 12 & 10 \\
\hline
\end{tabular}

It can be observed that the reduction in load carrying capacity is about $50 \%$ for a $2 \mathrm{~m}$ increase in span. However, it is important to note that these results are corresponding to the restrictions imposed on dimensions of the I-section. For example, D was restricted to $600 \mathrm{~mm}$ and hence higher Lcc are not possible for larger spans. The maximum pLcc can be observed to be $102.9 \%$ that is achieved for a Lcc of $10 \mathrm{kN} / \mathrm{m}$ over a span of $6 \mathrm{~m}$. Hence higher saving in the material can be achieved for shorter spans.

\subsection{Variation of ER with Span for Different Lcc}

From Table 1, the following observations are made.

Table 7. (a) Variation of span with ER for Lcc $=10 \mathrm{kN} / \mathrm{m}$.

\begin{tabular}{cc}
\hline Span $\mathbf{( m )}$ & ER \\
\hline 6 & 0.6 \\
\hline 8 & 0.1 \\
\hline 10 & 0.1 \\
\hline 12 & 0.5 \\
\hline
\end{tabular}

Table 7. (b) Variation of span with ER for Lcc $=20 \mathrm{kN} / \mathrm{m}$.

\begin{tabular}{cc}
\hline Span (m) & ER \\
\hline 6 & 0.48 \\
\hline 8 & 0.5 \\
\hline 10 & 0.6 \\
\hline
\end{tabular}


From the above tables, it is observed that for optimum utilisation of the available cross section, ER has to be in between 0.1 to 0.6 if the load carrying capacity required is $10 \mathrm{kN} / \mathrm{m}$ and it has to be between 0.48 to 0.6 if the load carrying capacity required is $20 \mathrm{kN} / \mathrm{m}$.

\subsection{Variation of FF with Span for Different Lcc}

From Table 1, it is observed that, for a given load carrying capacity, the maximum prestressing force that can be applied decrease with span. This is due to larger span tending to buckle under high prestressing force. The following observations can also be made.

Table 8. (a) Variation of span with FF for $\mathrm{Lcc}=10 \mathrm{kN} / \mathrm{m}$.

\begin{tabular}{cc}
\hline Span (m) & FF \\
\hline 6 & 0.24 \\
\hline 8 & 0.03 \\
\hline 10 & 0.03 \\
\hline 12 & 0.3 \\
\hline
\end{tabular}

Table 8. (b) Variation of span with FF for $\mathrm{Lcc}=20 \mathrm{kN} / \mathrm{m}$.

\begin{tabular}{cc}
\hline Span (m) & FF \\
\hline 6 & 0.21 \\
\hline 8 & 0.12 \\
\hline 10 & 0.21 \\
\hline
\end{tabular}

From the above tables, it is observed that for optimum utilisation of the available cross section, FF has to be in between 0.03 to 0.3 if the load carrying capacity required is $10 \mathrm{kN} / \mathrm{m}$ and it has to be between 0.12 to 0.21 if the load carrying capacity required is $20 \mathrm{kN} / \mathrm{m}$.

\subsection{Variation of Range of $y_{t} / y_{b}$ with Span}

From Table 3, the range of the ratio of the distance of Neutral axes from top flange to that of the bottom flange for different spans are observed to be as follows.

Table 9. Variation of range of $y t / y b$ with span.

\begin{tabular}{cc}
\hline Span (m) & Range of $\mathbf{y}_{\mathbf{t}} / \mathbf{y}_{\mathbf{b}}$ \\
\hline 6 & 0.57 to 1.0 \\
\hline 8 & 0.68 to 0.89 \\
\hline 10 & 0.67 to 0.97 \\
\hline 12 & 0.75 \\
\hline
\end{tabular}

It is to be noted here that closer the value of $\mathrm{y}_{\mathrm{t}} / \mathrm{yb}_{\mathrm{b}}$ to 1 , lesser is the asymmetry in the cross-section. As all the sections under consideration are optimum sections, we can understand from the table that the optimum cross-section approaches symmetry as the span increases.

\subsection{Variation of Deflection with Span}

From Table 1, the variation of the maximum percentage decrease in deflection and corresponding load carrying capacity for different spans are observed to be as follows (Table 10). 
Table 10. Variation of maximum pdef with span and Lcc.

\begin{tabular}{ccc}
\hline Span $(\mathrm{m})$ & Maximum pdef & Lcc \\
\hline 6 & 37.6 & 50.1 \\
\hline 8 & 19.2 & 20 \\
\hline 10 & 29.6 & 20 \\
\hline 12 & 39.6 & 10 \\
\hline
\end{tabular}

The maximum \% decrease in deflection is observed to be 39.6 for a span of $12 \mathrm{~m}$ and Lcc of $10 \mathrm{kN} / \mathrm{m}$.

\subsection{Variation of Range of A/WA with span}

From Table 3, the range of ratios of total area to area of web for different spans is as follows (Table 11).

Table 11. Variation of range of A/WA with span.

\begin{tabular}{cc}
\hline Span (m) & Range of A/WA \\
\hline 6 & 2.21 to 4.57 \\
\hline 8 & 1.34 to 5.14 \\
\hline 10 & 3.68 to 3.86 \\
\hline 12 & 3.45 \\
\hline
\end{tabular}

\subsection{Variation of Range A/TFA with Span}

From Table 3, the ratios of total area to the area of top flange for different spans are observed to be as follows (Table 12).

Table 12. Variation of range of A/TFA with span.

\begin{tabular}{cc}
\hline Span $(\mathrm{m})$ & Range of A/TFA \\
\hline 6 & 2.05 to 2.73 \\
\hline 8 & 2.2 to 3.41 \\
\hline 10 & 2.11 to 2.57 \\
\hline 12 & 2.29 \\
\hline
\end{tabular}

\subsection{Variation of Range $A / B F A$ with Span}

From Table 3, the range of the ratios of total area to the area of bottom flange for different spans is observed to be as follows (Table 13).

Table 13. Variation of range of A/BFA with span.

\begin{tabular}{cc}
\hline Span (m) & Range of A/BFA \\
\hline 6 & 2.56 to 7.40 \\
\hline 8 & 2.86 to 6.33 \\
\hline 10 & 2.84 to 3.92 \\
\hline 12 & 3.67 \\
\hline
\end{tabular}

\subsection{Variation of Range TFA/BFA with Span}

From Table 3, the range of the ratios of the area of top flange to the area of bottom flange for different spans is observed to be as follows (Table 14). 
Table 14. Variation of range of TFA/BFA with span.

\begin{tabular}{cc}
\hline Span (m) & Range of TFA/BFA \\
\hline 6 & 1.0 to 3.06 \\
\hline 8 & 1.3 to 1.86 \\
\hline 10 & 1.11 to 1.86 \\
\hline 12 & 1.61 \\
\hline
\end{tabular}

\subsection{Variation of Range FA/WA with Span}

From Table 3, the ratios of the total flange area to the total web area for different spans are observed to be as follows (Table 15).

Table 15. Variation of range of FA/WA with span.

\begin{tabular}{cc}
\hline Span $(\mathbf{m})$ & Range of FA/WA \\
\hline 6 & 1.21 to 3.57 \\
\hline 8 & 1.08 to 2.44 \\
\hline 10 & 2.68 to 2.86 \\
\hline 12 & 2.45 \\
\hline
\end{tabular}

\subsection{Variation of Different Stress Ratios with Span and Load Carrying Capacity}

From Tables 1, 2, 3, 4 and 5, the following observations can be made.

1) For all spans considered, the ratio of DSRT is 1 for all load carrying capacities. This means that the output of the program is a cross-section for which stress at top fiber is equal to the design stress at top fiber. It is important to note that in case of simply supported steel beams subjected to gradually applied loads, the top fiber attains the maximum permissible stress prior to the bottom flange.

2) For all spans considered, the ratio of TSRT is close to Zero for all load carrying capacities. This means that the output of program is a cross-section and corresponding magnitude of prestress and eccentricity which nullify the compressive stress due to dead load. The maximum value of it is observed to be -0.06 , for a load carrying capacity of $10 \mathrm{kN} / \mathrm{m}$ and span of $10 \mathrm{~m}$.

3) Considering all spans and load carrying capacities, the ratio of DSRB is in between 0.25 and 0.87 . The minimum ratio of 0.25 is corresponding to span of $12 \mathrm{~m}$ with a load carrying capacity of 10 $\mathrm{kN} / \mathrm{m}$. The maximum ratio of 0.87 is observed for a span of $6 \mathrm{~m}$ with a load carrying capacity of $60 \mathrm{kN} / \mathrm{m}$. It is important to note that the higher is the magnitude of DSRB, more effective is the utilisation of the tension zone of the cross-section.

4) Considering all spans and load carrying capacities, the ratio of TSRB is in between -0.04 and 0.83 . The minimum ratio of -0.04 is corresponding to span of $10 \mathrm{~m}$ with a load carrying capacity of 10 $\mathrm{kN} / \mathrm{m}$. The maximum ratio of 0.83 is observed for a span of $6 \mathrm{~m}$ with a load carrying capacity of $50 \mathrm{kN} / \mathrm{m}$.

5) Considering all spans and load carrying capacities, the ratio of TSR is in between -3.08 to 0.77 . However, the absolute minimum value is 0.01 and the absolute maximum is 3.08 . The absolute minimum ratio of 0.01 is corresponding to span of $10 \mathrm{~m}$ with a load carrying capacity of $20 \mathrm{kN} / \mathrm{m}$. The absolute maximum ratio of 3.08 is observed for a span of $8 \mathrm{~m}$ with a load carrying capacity of $10 \mathrm{kN} / \mathrm{m}$. It is important to note that the higher is the magnitude of absolute value of this ratio, the utilisation of the cross section at transfer of prestress is effective.

6) Considering all spans and load carrying capacities, the ratio of WSR is in between -1.57 to -0.64 . These are also the absolute maximum and absolute minimum values respectively. The absolute minimum ratio of 0.64 is observed corresponding to span of $6 \mathrm{~m}$ with a load carrying capacity of $60 \mathrm{kN} / \mathrm{m}$. The absolute maximum ratio of 1.57 is observed for a span of $12 \mathrm{~m}$ with a load carrying capacity of $10 \mathrm{kN} / \mathrm{m}$. It is important to note that the higher is the magnitude of absolute value of this ratio, effective is the utilisation of the cross section at working loads. 


\section{Conclusions}

Based on the study of variables within the scope of this research, the following conclusions can be drawn.

1) For a given load carrying capacity and span, ER has to be in between 0.45 to 0.7 for optimum utilization of the cross-section of prestressed steel I-beam.

2) For Unsymmetrical I-Beams, the maximum prestress and eccentricity that can be applied can be increased and hence a higher load carrying capacity can be achieved.

3) It can be observed that the reduction in load carrying capacity is almost $50 \%$ for an increase in span of $2 \mathrm{~m}$ when the overall depth of the cross-section was restricted to $600 \mathrm{~mm}$.

4) With reference to unsymmetrical prestressed steel I-beams, higher saving in the material can be achieved for shorter spans and lower Load carrying capacities.

5) For a given load carrying capacity, the maximum prestressing force that can be applied decrease with span.

6) Prestressing permits longer spans for the same load when compared to un-prestressed steel beams in the deflection point of view.

7) In case of simply supported steel beams subjected to gradually applied loads, the top fiber attains the maximum permissible stress prior to the bottom flange.

8) The maximum prestressing force that can be applied decreases with span. This is due to larger spans tending to buckle under high prestressing force. The ratio of prestress to permissible bending compressive stress values is observed to be in between 0.25 to 0.3 for a given load carrying capacity.

9) The ratio of prestress to bending compressive stress with load carrying capacity has to be in between 0.15 to 0.3 for optimum utilization of cross section for a given span.

10) For optimum sections, the ratio of bottom fiber stress at transfer to the permissible stress for different spans varies from 0.6 to 1.0 .

The study presents some preliminary information on developing optimized dimensions for a prestressed steel beam. The authors assume the dimensions can easily achieve by welding plates of necessary dimensions. The spans and loads considered in this study are primarily meant to be adopted in residential and Industrial buildings.

\section{References}

[1] S. A. Whipple, Work on Bridge Building. Utica: H. H. Curtiss, 1847.

[2] F. Dischinger, "Stahlbruecken im Verbund nit Stahlbeton Druckplat-ten bei gleichzeitiger Vorspannung durch hochwertige Seile," Der Baningenieur, vol. 24, no. 11\&12, pp. 321-332 \& 364-376, Nov.-Dec. 1949.

[3] B. Fritz, "Ueber die Berechnung und Konstruktion vorgespannter, Staehlerner Fachwerktr;iger," Der Stablbau, vol. 24, no. 8, pp. 169-174, Aug. 1955.

[4] L. Coff, "American engineer studies: Prestressing of structural steel," Civil Engineering, vol. 20, no. 11, pp. 64-65, Nov. 1950.

[5] G. P. Magnel, "Prestressed steel structures," The Structural Engineer, vol. 28, no. 11, pp. 285-295, Nov. 1950.

[6] G. P. Magnel, "Long prestressed steel truss erected for Belgian hangar," Civil Engineering, vol. 24, no. 10, pp. 38-39, Oct. 1954.

[7] R. L. Barnett, "Prestressed truss beams," Transaction of the American Society of Civil Engineers, vol. 83, no. ST2, pp. 1191-1-1191-22, Mar. 1957.

[8] P. F. Barnard, "Prestressed steel bridges," Iowa Highway Commission, Ames, 1960, unpublished.

[9] A. A. Vasiliev, "Optimum parameters of steel beams with single step prestressing," stroitelnaya mekbanika I raschet sooruzheniy, no. 1, 1961.

[10] E. V. Finn and F. H. Needham, "The use of prestressed steel in elevated roadways," The Structural Engineer, vol. 42, no. 1, pp. 5-18, Jan. 1964.

[11] A. M. Petrov, "On the parameters of prestressed steel beam," IVSLA, no. 1, pp. 9-14, 1965.

[12] A. M. Petrov, "On the choice of cross-section of prestressed steel beam," IVSLA, no. 9, pp. 3-6, 1967. 
[13] American Society of Civil Engineers, "Subcommittee 3 report on prestressed steel of joint ASCEAASHO committee on steel flexural members," American Society of Civil Engineers, Journal of the Structural Division, vol. 94, no. ST9. Sept. 1968, pp. 2033-2060.

[14] C. E. Ekberg, "Development and use of prestressed steel flexural members," Subcommittee 3 Report on Prestressed Steel of Joint ASCE-AASHO Committee on Steel Flexural Members, American Society of Civil Engineers, Journal of the Structural Division, vol. 94, no. ST9, pp. 2033-2060, Sept. 1968.

[15] P. Ferjencik, "Czechoslovak contribution in the field of pre-stressed steel structures," International Civil Engineering, vol. 11, no. 11, pp. 481-491, May 1972.

[16] M. Tochacek and F. G. Amrhein, "Which design concept for prestressed steel," Engineering JournalAmerican Institute of Steel Construction, vol. 8, no. 1, pp. 18-30, Jan. 1971.

[17] M. Tochacek and C. L Mehta, "Economical design of prestressed plate girder," Journal of the Structural Division, vol. 98, no. ST6, pp. 1273-1289, June 1972.

[18] E. Belenya and D. M. Gorovskii, "The analysis of steel beams strengthened by a tie rod," International Civil Engineering, vol. 11, no. 9, pp. 412-419, Mar. 1972.

[19] R. V. Kalburgi, "Prestressed flexural sections," The Structural Engineer, vol. 53, no. 6, pp. 264-270, Jun. 1975.

[20] S. I. AL-Noury, M. A. Choudhry, S. A. Ali, and S. Huq, "Behaviour of prestressed steel continuous beams of variable sections," Journal of Engineering and Applied Sciences, vol. 3, no. 3, pp. 151-160, 1986.

[21] M. S. Troitsky, Z. A. Zielinski, and N. F. Rabbani, "Prestressed steel continuous span girders," Journal of Structural Engineering, vol. 115, no. 6, 1989.

[22] M. A Bradford, "Buckling of prestressed steel girders," Engineering Journal-American Institute of Steel Construction, vol. 28, no. 3, pp. 98-101, 1991.

[23] M. G. R. Rao, "State of the art behavior of prestressed metal beams in flexure and improved methods of design," Ph.D. thesis, Andhra University, Visakhapatnam, A.P, India, 1993, p. 357.

[24] D. Russel and P. E. Syder, "Prestressed steel girders for single span bridges," Engineering JournalAmerican Institute of Steel Construction, vol. 32, no. 3, pp. 83-86, 1995.

[25] A. Valiente and M. Elices, "Premature failure of prestressed steel bars," Engineering Failure Analysis, vol. 5, no. 3. pp. 219-227, 1998.

[26] V. Nunziata, "Prestressed steel structures," in Proceedings of the Conference on to Construct in Steel: Structure and Arcbitecture at Technical Study of Civil Engineering, Palm Campania, Naples, NA, October 3th-5th, 1999, pp. 3-5.

[27] V. S. M. Raman Singh, D. K. Mohapatra, and R. K. Dhiman, "Prestressed steel bridge (case study)," in Proceedings of the International Seminar of Steel and Composite Bridges, 2002.

[28] L. M. Guptha, "Prestressed steel structures," in Proceedings of the Conference on Modern Trends in Steel Structures, Nagpur, February 2002, pp. K1-K7.

[29] J. Brodka and J. Klobukowki, ATOM Bridge Construction Method. 2002.

[30] Y. Ozcatalbas and A. Ozer, "Investigation of fabrication and mechanical properties of internally prestressed steel I-beam," Materials and Design, vol. 28, pp. 1988-1993, 2007.

[31] V. Ravindra, T. Venkateswarlu, and P. Markandeya Raju, "Computerized design of pre-stressed homogeneous steel beam," Journal of Structural Engineering, vol. 35, no. 2, pp. 104-109, 2008.

[32] B. Belletti and A. Gaspen, "Behavior of prestressed steel beams," Journal of Structural Engineering, vol. 136, no. 9, pp. 1131-1139, 2010.

[33] S. Park, T. Kim, K. Kim, and S.-N. Hong, "Flexural behavior of steel I-beam prestressed with externally unbonded tendons," Journal of Constructional Steel Research, vol. 66, pp. 125-132, 2010.

[34] R. Vipparthy and M. R. Ponnada, "Effect of loss of prestress on performance of prestressed steel Ibeam," Global Journal Engineering \& Applied Sciences, vol. 2, no. 1, pp. 81-87, 2012.

[35] J.-Y. Oh, D. H. Lee, and K. S. Kim, "Accordion effect of prestressed steel beams with corrugated webs,” Thin-Walled Structures, vol. 57, pp. 49-61, 2012.

[36] M. R. Ponnada and R. Vipparthy, "Analytical study on prestressed steel I-beam strengthened in compression by angles," Journal of the Institution of Engineers (India), series A 94, no. 3, pp. 139-151, 2013.

[37] V. Ravindra and P. Markandeya Raju, "Performance of prestressed homogeneous steel I-beam strengthened in compression," Journal of Structural Engineering, vol. 40, no. 4, pp. 343-350, 2013.

[38] M. Raju Ponnada and R. Vipparthy, "Improved method of estimating deflection in prestressed steel Ibeams," Asian Journal of Civil Engineering (BHRC), vol. 15, no. 2, pp. 307-320, 2014. 
[39] V. Ravindra and P. Markandeya Raju, "Optimum design of an unsymmetrical, laterally unsupported prestressed homogenous steel I-beam," in the Proceedings of $6^{\text {th }}$ International Conference on Steel and Alluminium Structures (ICS AS07), Oxford Brookes University, London, UK, July 2007, pp. 301-308.

[40] T. Pothisiri and N. Hemathulin, "Test data on intumescent fire protection for structural steel sections in Thailand," Engineering Journal, vol. 16, no. 2, pp. 85-92, 2012. doi:10.4186/ej.2012.16.2.85

[41] A. Lenwari and H. Chen, "Finite element analysis of distortion-induced web gap stresses in multi-I Girder steel bridges," Engineering Journal, vol. 17, no. 1, pp. 95-110, 2012. doi:10.4186/ej.2013.17.1.95

[42] V. Ky, A. Lenwari, and T. Thepchatri, "Optimum design of steel structures in accordance with AISC 2010 specification using heuristic algorithm," Engineering Journal, vol. 19, no. 4, pp. 71-81, 2015. doi:10.4186/ej.2015.19.4.71

[43] K. Phuvoravan and P. Ponsorn, "Nonlinear finite element analysis to evaluate lateral torsional buckling moment of elliptical cellular steel beams," Engineering Journal, vol. 21, no. 1, pp. 93-108, 2017. doi:10.4186/ej.2017.21.1.93

[44] IS Hand Book for Structural Engineers-1 (SP 6(1)-1998: Structural Steel Sections), Bureau of Indian Standards, New Delhi.

[45] Indian Standard Code of Practice for General Construction in Steel, IS 800 1984, Bureau of Indian Standards, New Delhi, 1984.

[46] S. P. Timoshenko and J. M. Gere, Theory of Elastic Stability, 2nd ed. New York: McGraw-Hill, 1961.

[47] F. Bleich, Buckling Strength of Metal Structures. New York: McGraw-Hill, 1952.

[48] B. G. Johnston, Guide to Design Criteria for Metal Compression Members, 2nd ed. New York: John Wiley, 1966.

[49] T. V. Galambos, Structural Members and Frames. New Jersey: Prentice-Hall, 1968.

[50] Handbook of Structural Stability, Column Research Committee of Japan, 1971.

[51] H. G. Allen and P. S. Bulson, Background to Buckling. 1980.

[52] American Society of Civil Engineers, Stability of Structure Under Static and Dynamic Loads. ASCE, 1977.

[53] G. C. Lee, "A survey of literature on the lateral instability of beams," Welding Research Council Bulletin, vol. 63, p. 50, Aug. 1960.

[54] N. S. Trahair, "The bending stress rules of the draft AS CA 1," Journal of Institution of Engineers Australia, vol. 38, no. 6, June 1966.

[55] N. S. Trahair, "Elastic stability of I-beam element in rigid-jointed frames," Journal of Institution of Engineers Australia, vol. 38, no. 7-8, Jul.-Aug. 1966.

[56] N. S. Trahair, "Elastic stability of propped cantilevers," Civil Engineering Transactions, Institution of Engineering, Australia, vol. CE10, no. 1, pp. 94-100, April 1968.

[57] J. M. Leigh, B. F. Thomas, and M. G. Lay, Safe Load Tables for Laterally Unsupported Angles. North Sydney, Australian Institute of Steel Construction, 1971. 


\section{Appendix A - Notations}

$A=$ Area of cross-section of the beam

$\mathrm{BFA}=$ area of the tension flange or bottom flange

$\mathrm{BI}_{\mathrm{x}}=$ Moment of inertia of the I-Section about $\mathrm{X}-\mathrm{X}$ axis $\left(\mathrm{mm}^{4}\right)$

$\mathrm{BI}_{\mathrm{y}}=$ Moment of inertia of the I-Section about $\mathrm{Y}-\mathrm{Y}$ axis $\left(\mathrm{mm}^{4}\right)$

$C=$ Crippling stress $\left(\mathrm{N} / \mathrm{mm}^{2}\right)$

$\mathrm{d}=$ depth of web

def $=$ Net downward deflection due to prestressing and live load

def1 $=$ Upward deflection due to prestressing force and dead load (before application of live load)

$\mathrm{dl}=$ dead load or self-weight of the beam

$\mathrm{D}=$ Total depth of the beam $(\mathrm{mm})$

$\mathrm{d}=$ depth of the web

DSR $=$ Design Stress Ratio $=\sigma_{c s} / \sigma_{t s}$

DSRB $=$ Design Stress Ratio at bottom fiber for working loads $=\sigma_{b w} / \sigma_{t s}$

DSRT $=$ Design Stress Ratio at top fiber for working loads $=\sigma_{t w} / \sigma_{c s}$

$\mathrm{e}=$ eccentricity $(\mathrm{mm})$

$\mathrm{e}_{\min }=$ minimum eccentricity

$\mathrm{e}_{\max }=$ maximum eccentricity

$\mathrm{E}=$ Modulus of Elasticity of the material of beam (steel)

$\mathrm{E} \times \mathrm{I}_{\mathrm{x}}=$ Flexural rigidity of the beam cross-section

$\mathrm{ER}=$ Eccentricity ratio $=\mathrm{e} / \mathrm{D}$

$\mathrm{FA}=$ sum of the areas of top and bottom flanges or total flange area

$\mathrm{FF}=$ Force factor $=\mathrm{P} /\left(\sigma_{\mathrm{bc}} \mathrm{xA}\right)$

Fy $=$ Permissible yield stress of steel

$\mathrm{h}=$ Depth of the root of the fillet from the top of the flange

$\mathrm{I}_{\mathrm{x}}=$ Moment of Inertia about centroidal X-X axes $\left(\mathrm{mm}^{4}\right)$

$k_{1}=$ Coefficient of $f_{c b}$

$k_{2}=$ Coefficient of $f_{c b}$ which depends on $\omega$

$1=$ span of the beam $(\mathrm{mm})$

$l_{\max }=$ Maximum allowable span of un-prestressed section after strengthening the flange $(\mathrm{s})(\mathrm{mm})$ 
Lcc $=$ Live load carrying capacity of the prestressed beam

$\mathrm{M}_{\mathrm{dl}}=$ Bending moment due to self weight alone

$\mathrm{M}_{\mathrm{tl}}=$ Bending moment due to total load (self weight + live load)

$\mathrm{M}_{\max }=$ Maximum Bending Moment (kN.m)

$\mathrm{M}_{\mathrm{X}}=$ Bending Moment at a distance ' $\mathrm{x}$ ' from left support

pDef $=$ percentage decrease in deflection due to prestressing

pLcc $=$ percentage increase in the load carrying capacity of the prestressed beam with respect to unprestressed beam

$\mathrm{P}=$ Magnitude of Prestressing force $(\mathrm{kN})$

$\mathrm{P}_{\max }=$ Maximum prestressing force that can be applied

$\mathrm{r}_{\mathrm{x}}=$ radius of gyration about centroidal $\mathrm{X}-\mathrm{X}$ axes

$r_{y}=r=$ radius of gyration about centroidal $Y-Y$ axes

$\mathrm{t}_{\mathrm{bf}}=$ Thickness of bottom flange (for asymmetrical I-sections)

$t_{f}=$ Thickness of flange (for symmetrical I-sections)

$\mathrm{t}_{\mathrm{ff}}=$ Thickness of top flange (for asymmetrical I-sections)

$\mathrm{t}_{\mathrm{w}}=$ Thickness of web (for symmetrical and asymmetrical I-sections)

$\mathrm{TFA}=$ area of the compression flange or top flange

TSR $=$ Stress ratio at transfer $=\sigma_{t n l} / \sigma_{b n l}$

$\mathrm{TSRB}=$ Design Stress Ratio at bottom fiber at transfer $=\sigma_{b n l} / \sigma_{c s}$

TSRT $=$ Design Stress Ratio at top fiber at transfer $=\sigma_{\text {tnl }} / \sigma_{t s}$

$\mathrm{V}=$ Maximum shear force

$\mathrm{w}=$ load carrying capacity of the un-prestressed beam $(\mathrm{kN} / \mathrm{m})$

$\mathrm{w}_{\mathrm{tl}}=$ total load on the prestressed steel beam including self-weight $(\mathrm{kN} / \mathrm{m})$

$\mathrm{w}_{\mathrm{bf}}=$ width of bottom flange (for asymmetrical I-sections)

$\mathrm{w}_{\mathrm{f}}=$ width of flange (for symmetrical I-sections)

$\mathrm{w}_{\mathrm{tf}}=$ width of top flange (for asymmetrical I-sections)

$\mathrm{WA}=$ area of the web

WSR $=$ Stress ratio at working loads $=\sigma_{t w} / \sigma_{b w}$

$\mathrm{yb}_{\mathrm{b}}=$ distance of the centroidal $\mathrm{X}-\mathrm{X}$ axes from bottom most fiber

$\mathrm{y}_{\mathrm{t}}=$ distance of the centroidal $\mathrm{X}-\mathrm{X}$ axes from top most fiber 
$Z_{\mathrm{xt}}=$ Section modulus at top fibre about centroidal $\mathrm{X}-\mathrm{X}$ axes

$\mathrm{Z}_{\mathrm{xb}}=$ Section modulus at bottom fibre about centroidal $\mathrm{X}-\mathrm{X}$ axes

$\mathrm{Z}_{\mathrm{y}}=$ Section modulus about centroidal $\mathrm{Y}-\mathrm{Y}$ axes

$\sigma_{\mathrm{cs}}=$ Allowable bending compressive stress $\left(\mathrm{N} / \mathrm{mm}^{2}\right)$

$\sigma_{\mathrm{ts}}=$ Allowable bending tensile stress $\left(\mathrm{N} / \mathrm{mm}^{2}\right)$

$\sigma_{d s}=$ permissible direct compressive stress (Mpa)

$\sigma_{\mathrm{bnl}}=$ Stress in bending compression at bottom fiber due to dead load alone $\left(\mathrm{N} / \mathrm{mm}^{2}\right)$

$\sigma_{\mathrm{tnl}}=$ Stress in bending compression at top fiber due to dead load alone $\left(\mathrm{N} / \mathrm{mm}^{2}\right)$

$\sigma_{\mathrm{tw}}=$ Stress in bending compression at top fiber due to dead load as well as live load $\left(\mathrm{N} / \mathrm{mm}^{2}\right)$

$\sigma_{\mathrm{bw}}=$ Stress in bending compression at bottom fiber due to dead as well as live load $\left(\mathrm{N} / \mathrm{mm}^{2}\right)$

$\tau=$ Maximum sheer stress $\left(\mathrm{N} / \mathrm{mm}^{2}\right)$

$\tau_{\text {cal }}=$ Shear stress induced in member (MPa)

$\omega=$ It is the ratio of $I_{y}$ of compression flange to $I_{y}$ of gross 